\title{
Pounding force assessment in performance-based design of bridges
}

\author{
Jaime Vega , Ignacio del Rey and Enrique Alarcon
}

\begin{abstract}
SUMMARY
Bridges with deck supported on either sliding or elastomeric bearings are very common in mid-seismicity regions. Their main seismic vulnerabilities are related to the pounding of the deck against abutments or between the different deck elements. A simplified model of the longitudinal behavior of those bridges will allow to characterize the reaction forces developed during pounding using the Pacific Earthquake Engineering Research Center framework formula. In order to ensure the general applicability of the results obtained, a large number of system parameter combinations will be considered. The heart of the formula is the identification of suitable intermediate variables. First, the pseudo acceleration spectral value for the fundamental period of the system $\left(\mathrm{Sa}\left(T_{s}\right)\right)$ will be used as an intensity measure (IM). This IM will result in a very large non-explained variability of the engineering demand parameter. A portion of this variability will be proved to be related to the relative content of high-frequency energy in the input motion. Two vector-valued IMs including a second parameter taking this energy content into account will then be considered. For both of them, a suitable form for the conditional intensity dependence of the response will be obtained. The question of which one to choose will also be analyzed. Finally, additional issues related to the IM will be studied: its applicability to pulse-type records, the validity of scaling records and the sufficiency of the IM.
\end{abstract}

KEY WORDS: seismic performance; pounding; PEER formula

\section{INTRODUCTION}

Earthquakes can induce pounding between neighboring structures or different parts of the same structure. This phenomenon can be explained by differences in vibration characteristics leading to out-of-phase motion or insufficient spacing. Extensive pounding related damage have been reported after many events (i.e. Mexico City 1985, Loma Prieta 1989, or Kobe 1995) [1]. 
Sometimes, damage only affects non-structural elements, but this is not always the case. Even if repair costs are not as important as those for structural components, their amount may not be a negligible part of the total costs.

During the last decades, progress in computer's speed and capacity has allowed the use of more comprehensive models, thus increasing the understanding of pounding. At the same time, some events have provided a lot of information to the research community. A primary concern has been the estimation of the gap size between buildings needed to avoid pounding [2]. More recently, Lin and Weng [3] assessed the probability of pounding considering two buildings.

Quite surprisingly, the forces developed during impacts have not received the same attention. Ma and Pantelides [4] have studied the effect of gap size and structural damping on maximum reaction forces between deck and abutment on a simplified model, but they only considered a single record. An interesting approach is the one proposed by Ruangrassamee and Kawashima [5], or by Jankowski [6], in relation with the displacement or pounding force response spectrum. Yet, very few records have been used, and there is no statistical characterization of reaction forces. Other parametric studies on more complicated models can be found for both buildings [7] and bridges [8], but the same remarks apply to them. Since some failure modes are related to pounding forces, their characterization may allow more refined performance-based design (PBD) and reliability assessment.

The use of Pacific Earthquake Engineering Research (PEER) Center formula [9] is very common in PBD. It splits a decision variable (DV) (i.e. one allowing the assessment of the adequacy of the design) in terms of other intermediate variables: intensity measures (IM), engineering demand parameters (EDP) and damage measures (DM). Thus, the vector of DVs is obtained from conditional probabilities' estimates. One key benefit of the PEER formula is that through disaggregation, the problem is split into separate ones, which may be solved in a modular way.

This work is dedicated to the characterization of reaction forces produced by pounding using the PEER framework formula. Further steps toward the characterization of DV will not be discussed here. As a result of the modularity of the framework, these steps are not different from other examples available in the literature [10]. The structural type studied will be bridges where the deck is supported either on sliding or elastomeric bearings. This type is commonly found in mid-seismicity regions like the south-east of Spain. In order to simplify the problem, the example chosen is a bridge where the deck is continuous and pounding is only possible between deck and abutments, mainly due to insufficient seismic gap.

\section{PEER FRAMEWORK FORMULA}

Performance-based earthquake engineering consists of the evaluation, design and construction of structures to meet seismic performance objectives that are meaningful for the structures' stakeholders. In this field, the methodology developed by the PEER Center has gained great popularity. This methodology is based on the disaggregation of probabilities and the numerical integration of conditional probabilities.

The objective is to estimate the value of a vector of DVs, such as annual earthquake loss. These variables are assumed to allow assessing the adequacy of the design.

The first step is the Hazard Analysis, in which mean annual rate of exceeding a given value for a particular ground-shaking intensity measure IM (scalar or vector valued) is evaluated. Next step, usually involving a series of nonlinear time-history analysis of a structural model, is the 
evaluation of response in terms of EDPs, conditioned on IM. In the considered pounding problem, the reaction force will be the EDP of interest. Finally, a vector of DM is defined conditional to demand, based on expert opinion or experimental data.

PEER formula, splitting DV probability in terms of the conditional probabilities of the intermediate variables IM, EDP and DM stands:

$$
\lambda(\mathrm{d} v)=\iiint G(\mathrm{~d} v \mid \mathrm{d} m) \mathrm{d} G(\mathrm{~d} m \mid \operatorname{edp}) \mathrm{d} G(\operatorname{edp} \mid \mathrm{im})|\mathrm{d} \lambda(\mathrm{im})|
$$

where $\lambda(x)$ denotes the mean rate of $x<X$ events per year and $G(x \mid y)$ denotes the conditional complementary cumulative function for random variable $\mathrm{X}$ given $Y=y$.

This study will be bounded to the first step of the procedure. The goal is to assess the mean annual frequency, $\lambda(\mathrm{edp})$, of (maximum) reaction forces that take place during pounding:

$$
\lambda(\operatorname{edp})=\int G(\operatorname{edp} \mid \operatorname{im})|\mathrm{d} \lambda(\operatorname{im})|
$$

where EDP is a (scalar) random variable representing the (maximum) value of reaction forces taking place during pounding.

Selection of an appropriate IM is the first task when applying the procedures. The literature provides examples of IM suitable for other problems, that could be used here, provided that they fulfill the sufficiency condition [11]. Sufficiency means that the IM provides all the information allowing the assessment of the parameter of interest. It is well accepted that the pair magnitude ( $M$, describing the source) and distance ( $R$, taking attenuation into account) are able to characterize the intensity produced by an earthquake at a given location. In the case of the assessment of an EDP, an IM will be said to be sufficient if

$$
\operatorname{Pr}(\operatorname{edp} \mid \mathrm{im}, M, R) \approx \operatorname{Pr}(\mathrm{edp} \mid \mathrm{im})
$$

This condition can only be proved to be match if $G(\operatorname{edp} \mid \mathrm{im})$ is known, which is not the case. Thus, selection of IM and characterization of $G(\mathrm{edp} \mid \mathrm{im})$ will be performed simultaneously.

\section{SIMPLIFIED MODEL}

\subsection{Literature review}

Pounding is a very complex phenomenon where friction, plastification, creeping or even local fracture can take place. Forces involved act during time lapses that are very small compared with the structural vibration periods. In addition, stress waves produced by those forces propagate inside the colliding bodies. All the above-mentioned factors result in great difficulties for an accurate modeling of the phenomenon.

First attempts to model pounding on buildings can be found in [2], where the goal was to estimate the suitable gap to avoid it. More recently, pounding between deck and abutments or between different deck portions has been studied. Results have highlighted the importance of pounding in modifying some demand parameters such as bending moments or base shear [8].

Two main approaches have been chosen for modeling pounding. First, the stereo mechanical approach, that assumes an instantaneous impact, and uses a restitution coefficient to establish the 
state of the system after shock. Its application is very limited because of its main assumption. In this case, reaction forces are the key unknown and these models do not account for them.

The second approach is the use of contact-elements, which are activated whenever impact takes place. When the element is linear viscoelastic, they follow the Kelvin-Voigt models [2, 8]. Their main disadvantage is that they provide a uniform energy dissipation all along the shock, which is not consistent with experimental evidence. In addition, with these models, a negative reaction force takes place just before the end of the contact. More recently, Hertz models have been used [1, 12]. They provide a better fit with experimental results, although there are not many of them. For instance, Muthukamar and DesRoches [12] report a comprehensive inventory of experimental data available, including only five references. The authors conclude that, with this support, it is a difficult task to a priori choosing a restitution coefficient, the key parameter of all models.

\subsection{The model and its integration}

The simplified model (Figure 1) consists of a single degree of freedom (SDF) system $\left(M, K_{s}, C_{s}\right)$ that represents the behavior before pounding takes place. If gap sizes are exceeded, visco-elastic elements $\left(K_{b}, C_{b}\right)$ allow pounding modeling. They have been chosen instead of the Hertz models because parameter selection as well as numerical solution is easier. Also, visco-elastic elements make it easy to fix parameters so as to fit experimental reaction forces [1]. Parameters $M, K_{s}, C_{s}$ and $K_{b}$ are not difficult to obtain. $C_{b}$ values are based on experimental data. For concrete structures, a value of $\zeta_{b}=0.14$ has been suggested [13]. Other experimental settings have led to values close to 28\% [14]. These differences may appear important. However, Agnastopoulos [2] reported that, in the case of in series pounding of buildings, displacement response was not very dependent on this value.

The following are the governing equations of the system response $u(t)$ :

$$
\begin{aligned}
& m \ddot{u}+\left(c_{s}+c_{b}\right) \dot{u}+k_{s} u+k_{b}(u-\text { gap })=-m \ddot{u}_{g}(t) \quad \text { if } u \geqslant \text { gap } \\
& m \ddot{u}+c_{s} \dot{u}+k_{s} u=-m \ddot{u}_{g}(t) \quad \text { if }|u|<\text { gap } \\
& m \ddot{u}+\left(c_{s}+c_{b}\right) \dot{u}+k_{s} u+k_{b}(u+\text { gap })=-m \ddot{u}_{g}(t) \quad \text { if } u \leqslant- \text { gap }
\end{aligned}
$$

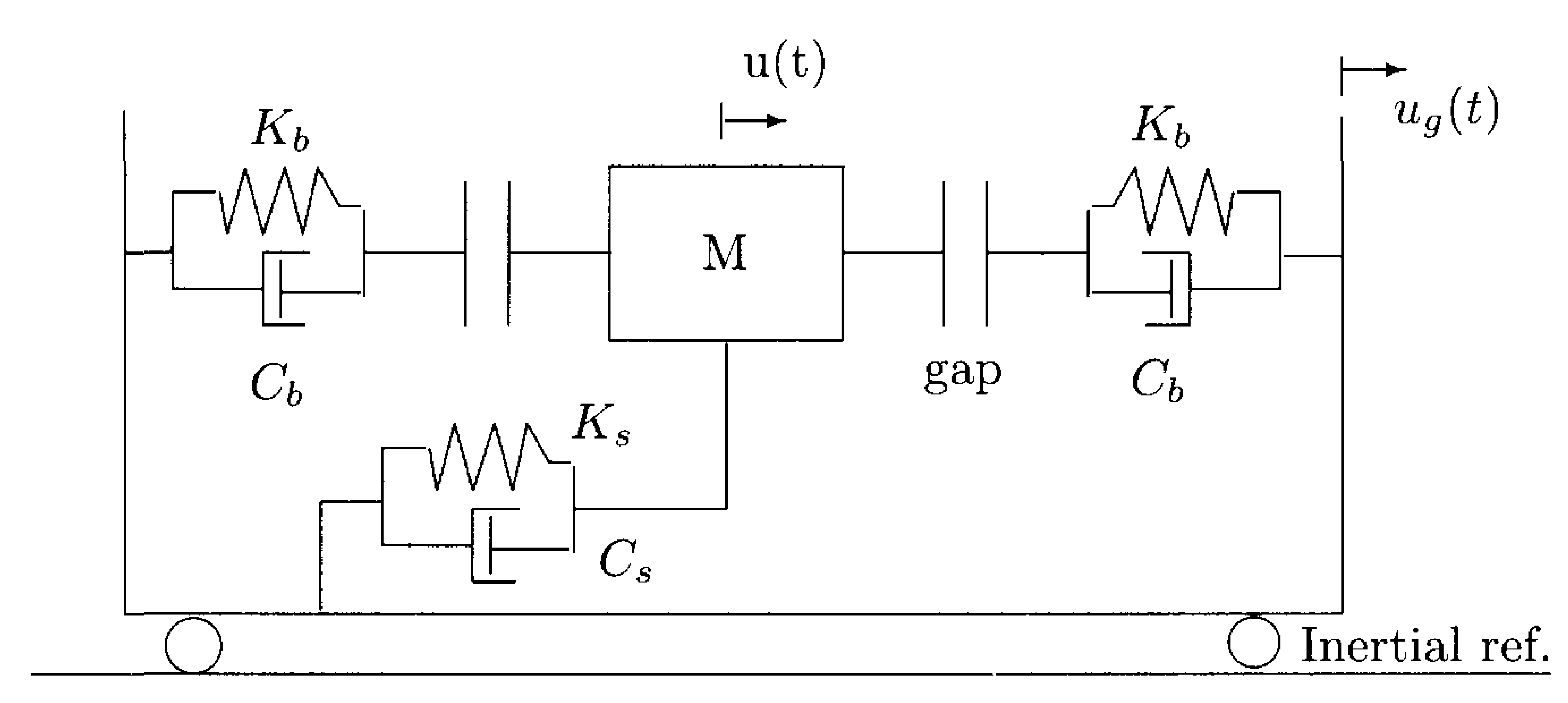

Figure 1. SDF model of the bridge's longitudinal behavior. 
The maximum value of reaction forces taking place during shocks, $R_{\max }$, is the response parameter of interest.

$$
R_{\max }=\max \left\{\begin{array}{ll}
\left(c_{s}+c_{b}\right) \dot{u}+k_{s} u+k_{b}(u-\text { gap }) & \text { if } u \geqslant \text { gap } \\
-\left(\left(c_{s}+c_{b}\right) \dot{u}+k_{s} u+k_{b}(u+\text { gap })\right) & \text { if } u \leqslant- \text { gap }
\end{array}\right\}
$$

Integration of the equations is performed using piecewise interpolation method. Different time intervals are chosen for events with or without contact.

\section{INTENSITY MEASURE (IM)}

\subsection{Selection of IM}

The criteria that guides the selection of IM is the sufficiency condition, or its ability to describe intensity without bias. Two conditions may be added. The first is the efficiency condition that measures the amount of effort required for estimations: the bigger the correlation between IM and EDP, the fewer samples shall be needed for an accurate parameter estimation. The second practical condition is its probability distribution $\lambda_{\mathrm{IM}}$ being available from standard Hazard Analysis. The last condition allows integration of Equation 2, thus ensuring the practical application of the procedure.

Let $\operatorname{Sd}\left(T_{s}, \zeta\right)$ be the spectral displacement (i.e. the maximum displacement of an SDF with natural vibration period $T_{s}$ and damping ratio $\zeta$ ). It is clear that, should this IM be considered, $R_{\max }$ values greater than zero will only be possible if $\mathrm{Sd}>$ gap. Given the direct relationship between the pseudo-acceleration spectrum ( $\mathrm{Sa}$ ) and $\mathrm{Sd}$, and given the fact that standard hazard studies provide hazard curves in terms of Sa, this IM seems to be a good candidate.

It is clear that there will be reaction force only if

$$
\frac{\text { gap }}{\operatorname{Sd}\left(T_{S}\right)} \leqslant 1
$$

The left-hand side of (6), or relative intensity, may also be used as IM. It is related to Sa as follows:

$$
\frac{\text { gap }}{\operatorname{Sd}\left(T_{s}\right)}=\frac{\mathrm{Sa}_{0}}{\omega_{s}^{2}} \frac{\omega_{s}^{2}}{\operatorname{Sd}\left(T_{s}\right)}=\frac{1}{\frac{\mathrm{Sa}}{\mathrm{Sa}_{0}}}
$$

where $\mathrm{Sa}_{0}=\omega_{n}^{2}$. gap is the spectral acceleration value that divides the intensity range in pounding and no-pounding regions.

This measure has some advantages compared with Sa. First, given a set of equally spaced points, the relative intensity provides a more detailed view of the range of intensities close to the one that sets pounding off. In this zone, as will be seen later, $R_{\max }$ has an erratic behavior. Second, intensity values range in the interval $[0,1]$. This may be helpful for applying certain mathematical tools.

\subsection{Record scaling and gap scaling}

In the definition of the relative intensity parameter, it seems clear that the same value may be achieved by scaling either the record or the gap. As we shall see, in both cases, response parameters are linked. 
Consider two systems with equal masses and stiffness, different gap sizes but excited to make the ratio gap/Sd equal. For system no. 1 , with gap size gap ${ }_{1}$, excited by $\ddot{u}_{g}(t)$, the value of the time history response is $\left(u_{1}(t)\right)$, and therefore, the maximum value of the pounding force $R_{\max , 1}$ may be obtained by solving the set of equations in (8):

$$
\begin{aligned}
m \ddot{u}_{1}+\left(c_{s}+c_{b}\right) \dot{u}_{1}+k_{s} u_{1}+k_{b}\left(u_{1}-\operatorname{gap}_{1}\right)=-m \ddot{u}_{g}(t) & \text { if } u \geqslant \operatorname{gap}_{1} \\
m \ddot{u}_{1}+c_{s} \dot{u}_{1}+k_{s} u_{1}=-m \ddot{u}_{g}(t) & \text { if }|u|<\operatorname{gap}_{1} \\
m \ddot{u}_{1}+\left(c_{s}+c_{b}\right) \dot{u}_{1}+k_{s} u_{1}+k_{b}\left(u_{1}+\operatorname{gap}_{1}\right)=-m \ddot{u}_{g}(t) & \text { if } u \leqslant-\operatorname{gap}_{1}
\end{aligned}
$$

System no. 2 has gap size gap $2=\lambda_{1}$ gap $_{1}$, and is excited by $\lambda_{1} \ddot{u}_{g}(t)$. Again, $u_{2}(t)$ and $R_{\max , 2}$ may be obtained by solving Equation 9:

$$
\begin{aligned}
m \ddot{u}_{2}+\left(c_{s}+c_{b}\right) \dot{u}_{2}+k_{s} u_{2}+k_{b}\left(u_{2}-\lambda_{1} \operatorname{gap}_{1}\right)=-m \lambda_{1} \ddot{u}_{g}(t) & \text { if } u \geqslant \operatorname{gap}_{2} \\
m \ddot{u}_{2}+c_{s} \dot{u}_{2}+k_{s} u_{2}=-m \lambda_{1} \ddot{u}_{g}(t) & \text { if }|u|<\operatorname{gap}_{2} \\
m \ddot{u}_{2}+\left(c_{s}+c_{b}\right) \dot{u}_{2}+k_{s} u_{2}+k_{b}\left(u_{2}+\lambda_{1} \operatorname{gap}_{1}\right)=-m \lambda_{1} \ddot{u}_{g}(t) & \text { if } u \leqslant-\operatorname{gap}_{2}
\end{aligned}
$$

It is clear that $u_{2}=\lambda_{1} u_{1}$ is the solution to (9). Therefore both values of $R_{\max }$ are linked as follows:

$$
R_{\max 2}=\max \left\{\lambda_{1}\left(c_{s}+c_{b}\right) \dot{u_{1}}+\lambda_{1} k_{s} u+\lambda_{1} k_{b}\left(u_{1}+\text { gap }\right)\right\}=\lambda_{1} R_{\max 1}
$$

This relation shows that, for a given relative intensity, response values are proportional to absolute intensity. In addition, it shows that calculations for incremental dynamic analysis (IDA, [15]) may be performed either by scaling records, or scaling gap size and then correcting the results with expression (10).

\subsection{Preliminary response study}

Figure 2(a) presents the IDA curve for a system $\left(T_{s}=1.5 \mathrm{~s}, \zeta_{b}=20 \%, k_{b} / k_{s}=10^{4}\right)$ considering El Centro record. Although its $R_{\max }$ values increases as $\mathrm{Sa}$ increases, some points do not behave
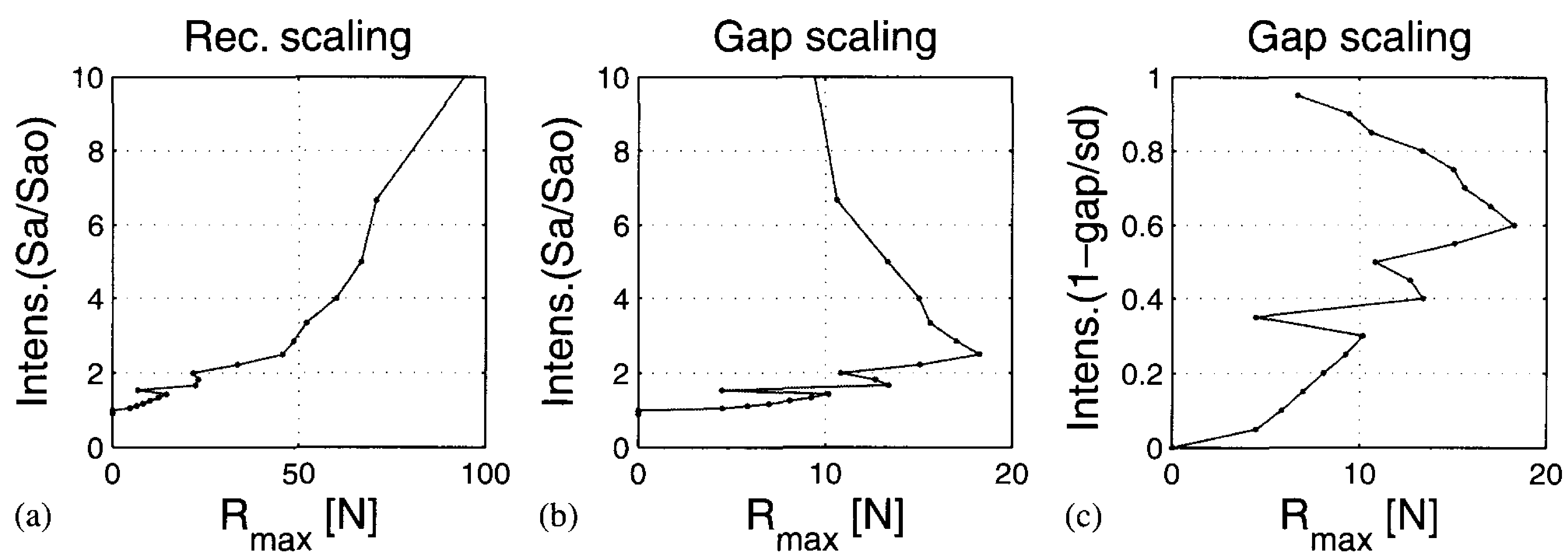

Figure 2. IDA curves. System parameters: $T_{s}=1.5 \mathrm{~s}, \zeta_{b}=20 \%, k_{b} / k_{s}=10^{4}$. Ground motion: El Centro station, NS component, Imperial Valley earthquake 1940. 
typically. Together with the typical IDA curve, two additional curves are presented. They have been computed for similar relative intensity values, but instead of scaling the time history acceleration record, gap size has been scaled. In Figure 2(b), $R_{\max }$ values are plotted against absolute intensity, while in (c), they are plotted directly against the relative intensity. The last two plots give a clearer view of the erratic behavior of $R_{\max }$.

\section{PARAMETRIC STUDY}

Once an IM has been selected, it is possible to estimate the distribution of $R_{\max }$ conditional on $\mathrm{Sa}\left(T_{s}\right)\left(G\left(r_{\max } \mid s_{a}\right)\right)$. This will be performed covering a wide range of combinations of both parameters defining the model and intensity values:

- SDF vibration periods: $T_{s}=1,1.5$ and $2 \mathrm{~s}$.

- Stop bearing to horizontal bearing stiffness relation $K_{b} / K_{s}: 10^{2}, 10^{3}, 10^{4}$ and $10^{5}$.

- Impact damping ratios. $\zeta_{b}$ values: 15,20 and $30 \%$.

- Relative intensity values: $0.1,0.2, \ldots, 0.9$

Randomness in ground motion will be represented by a set of 48 randomly sampled natural records. They have been chosen from a non homogeneous set of 94 rock records, selected from

Table I. Set of records used in the parametric study. Moment magnitude is presented whenever these data are available; otherwise, surface magnitude is used.

\begin{tabular}{lclcc}
\hline Event & Date & \multicolumn{1}{c}{ Station } & $M$ & $R(\mathrm{~km})$ \\
\hline San Fernando & $9 / 2 / 1971$ & LA - Hollywood SL & 6.6 & 21.2 \\
& & Gormon-Oso P.P. & & 48.1 \\
& & St.Felita dam & & 27.5 \\
Fruili & Whittier narrows dam & 6.5 & 37.1 \\
Fruili (R) & $6 / 5 / 1976$ & Tolmezzo & 5.3 & 21 \\
& $6 / 5 / 1976$ & Breginj-Fabrika IGLI & & 15 \\
Montenegro & & San Rocco & 6.9 & 15 \\
Imp. Valley & $15 / 4 / 1979$ & Forgaria-Cornio & 6.5 & 25 \\
& $15 / 10 / 1979$ & Petrovac-H.Oliva & & 10.6 \\
C. Lucano & & Calexico fire station & 6.9 & 16.5 \\
Preveza & $23 / 11 / 1980$ & El Centro array \#1 & 5.4 & 28 \\
Loma Prieta & $10 / 3 / 1981$ & Calitri & 6.9 & 21.8 \\
& $18 / 10 / 1989$ & Preveza-OTE build. & & 43.4 \\
& & Coyote lake dam (SW Abut) & & 77.4 \\
Potenza & & Fremont-Emerson court & & 36.1 \\
Landers & & Oakland-Title \& Trust & & 28 \\
Northridge & $5 / 5 / 1990$ & Palo Alto-1900 Embarc. & 5.8 & 69.5 \\
& $28 / 6 / 1992$ & Brienza & 7.4 & 9.2 \\
& $17 / 1 / 1994$ & Amboy & 6.7 & 47.6 \\
& & Arleta-Nordhoff fire sta. & & 41.9 \\
Kobe & & Downey-Co Maint bldg. & & 25.7 \\
& & LA-116th St. School & & 15.5 \\
\hline
\end{tabular}



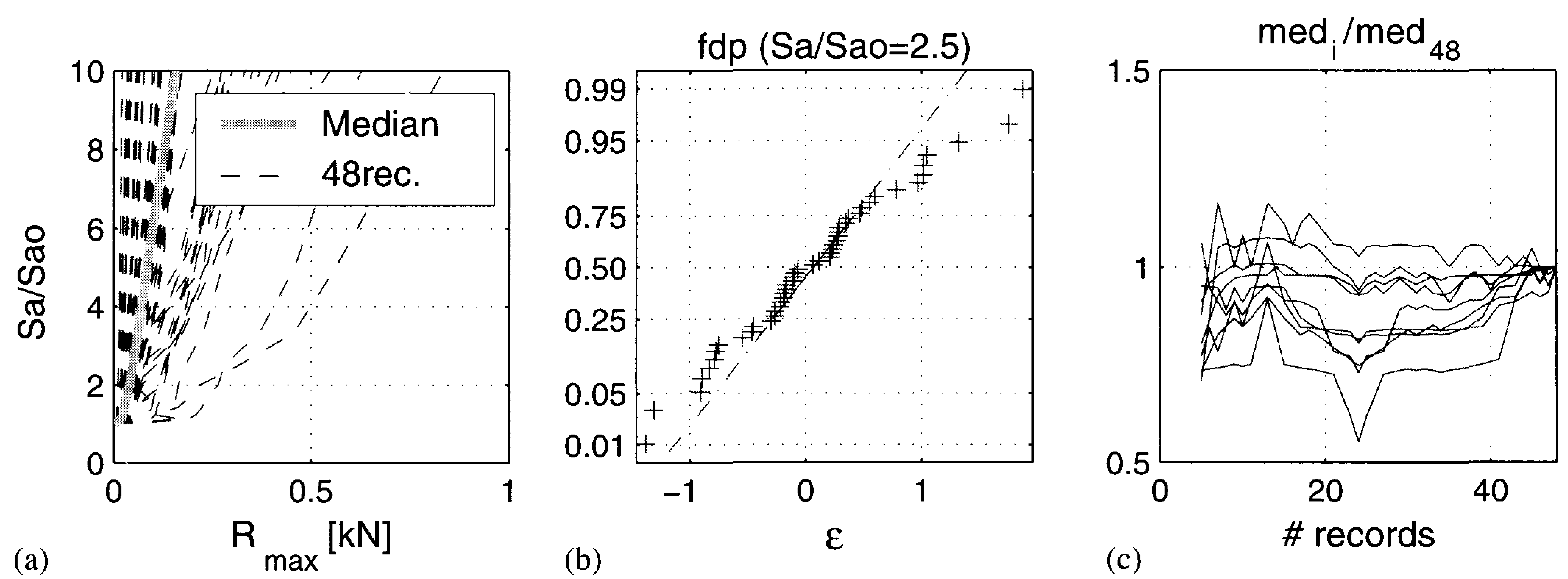

Figure 3. (a) IDA curves with median value; (b) normal probability plot of residuals for $\mathrm{Sa} / \mathrm{Sa}_{0}=2.5$; and (c) median values as a function of the number of samples.

System parameters: $T_{s}=2 \mathrm{~s}, \zeta_{b}=30 \%, K_{b} / K_{s}=10^{5}$.

PEER [16], and ESD [17] databases, covering a wide range of magnitudes and distances. From this set, recordings with epicentral distances smaller than $10 \mathrm{~km}$ have been disregarded, as they may contain pulses. The extrapolation of results to pulse records will be investigated ahead.

Then a second selection has been performed regarding the characteristics of high pass filters applied to raw recordings. In this study, vibration periods up to $2 \mathrm{~s}$ will be of interest. Since corner frequencies are slightly filtered, a limit has been set to $0.5 \mathrm{~Hz}\left(f_{\mathrm{c}} \leqslant 0.5 \mathrm{~Hz}\right)$.

This selection has reduced the sample to 48 accelerograms, corresponding to the horizontal recordings of 24 triaxial records (Table I).

A total of $3 \cdot 4 \cdot 3 \cdot 9 \cdot 48=15552$ time history analysis have been performed.

\section{REGRESSION MODEL FOR AN IM COMPOSED OF Sa(T $\left.T_{s}\right)$}

\subsection{Regression model}

The following common dependence between the $R_{\max }$ and the IM will be adopted $[18,19]$ :

$$
\begin{aligned}
& R_{\max }=\hat{R}_{\text {max }} \cdot \eta \\
& \hat{R}_{\max }=E\left[R_{\max } \mid \mathrm{Sa}\left(T_{s}\right)=x\right]=a \cdot \mathrm{Sa}\left(T_{s}\right)^{b}
\end{aligned}
$$

where $a$ and $b$ are the regression parameters to be estimated. The residuals $\varepsilon=\log \eta$ are assumed to be distributed normally: $\varepsilon \sim N\left(0, \sigma_{\varepsilon}\right)$.

$$
\varepsilon_{i}=\log \left(R_{\max , i}\right)-\log \left(\hat{R}_{\max }\right)
$$

Figure 3(a) shows 48 sample IDA curves together with the median. A good fit of the later may be obtained for intensities bigger than $\mathrm{Sa}_{0}$ using the least-squares method. However, the hypothesis 

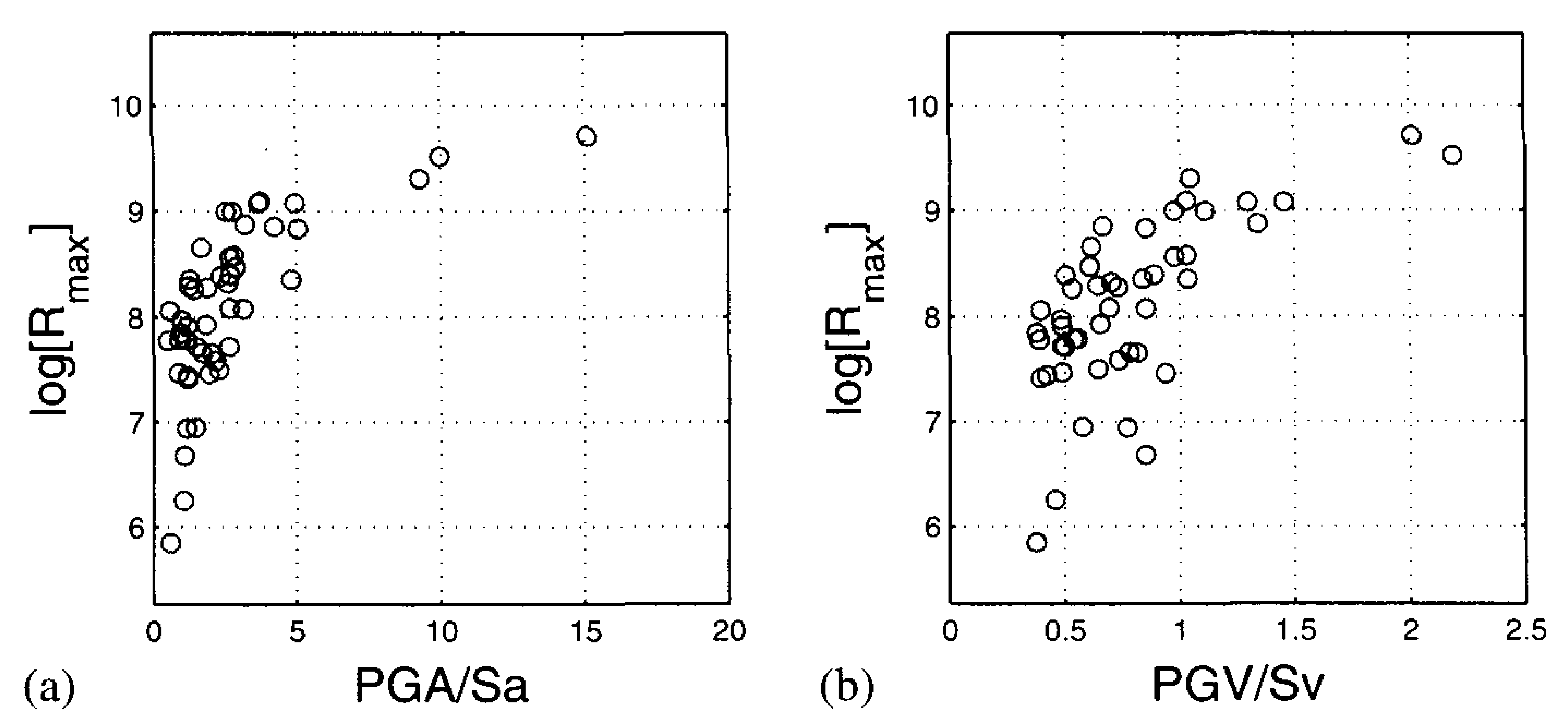

Figure 4. (a) Correlation between $R_{\max }$ and PGA/Sa( $\left.T_{s}\right)$ and (b) between $R_{\max }$ and PGA/Sv $\left(T_{s}\right)$. System parameters $T_{s}=1.5 \mathrm{~s}, \zeta_{b}=20 \%, K_{b} / K_{s}=10^{4}$, gap $/ \mathrm{Sd}=0.6$.

concerning the normality of the residuals $\varepsilon$ does not seems to be valid (Figure 3(b)). This difficulty may be overcome using another probability distribution.

Figure 3(c) shows the stabilization of (intensity conditioned) median values as the number of samples increases. These curves are not monotonously converging to one. Additional samples should provide no additional information after enough samples have been taken. The quantification of enough samples varies depending on the problem. In the case of response values conditional to an IM, there are many examples in the literature where median values become stable after around 10 samples [20].

One reason that may explain the above-mentioned insufficiency can be the existence of another parameter influencing $R_{\max }$ that has not been considered, such as another scalar IM, that is biasing the median value.

\subsection{Selection of an additional intensity parameter}

The existence of a second parameter is discussed next, by studying the correlation of $R_{\max }$ with a new scalar IM (given a fixed value of $\mathrm{Sa}\left(T_{S}\right)$ ). A good correlation will mean that the new IM does influence $R_{\max }$. Therefore, a vector-valued IM composed of both of them may have to be used.

The previously selected intensity parameter $\left(\mathrm{Sa}\left(T_{s}\right)\right)$ captures the information about energy in the free motion frequency range. Differences in response may be attributed to patterns in the ground motion that are important during pounding. The model may be seen as an SDF with lower vibration period (higher frequency) during shock. Two IMs that relate to high-frequency energy will be tested: peak ground acceleration (PGA) and peak ground velocity (PGV). Both parameters have been linked with damage [21,22].

Since the relative amount of energy is what distinguishes different records, both non-dimensional values of PGA and PGV will be used by dividing them by $\operatorname{Sa}\left(T_{s}\right)$ and $\operatorname{Sv}\left(T_{s}\right)$, respectively $\left(2 \pi / T_{s} \cdot \operatorname{Sv}\left(T_{s}\right)=\operatorname{Sa}\left(T_{s}\right)\right)$. This operation provides IMs that are not modified by scaling of records. In addition, the problem of collinearity that makes it difficult to separate the effect of each component [19] is avoided.

Figure 4 shows plots of $\log \left(R_{\max }\right)$ against the new IMs. In both cases positive correlation exists. Therefore, any of them, together with $\mathrm{Sa}\left(T_{s}\right)$ may be used as IMs. This will be analyzed in the following section. 


\section{REGRESSION MODEL WITH A VECTOR-VALUED IM}

\subsection{Linear regression model with two parameters}

The form of the dependence of $\log \left(R_{\max }\right)$ with the new intensity parameter has been found to be similar to the one used with the scalar IM $\mathrm{Sa}\left(T_{s}\right)$, that is, linear in logarithmic scale. Figure 5 shows that a linear dependence in the natural scale may only be valid for a reduced range of intensities.

The proposed regression model for vector-valued IM is an extension of the one in Equation (11). This time the estimated response value $\hat{R}_{\max }$ depends on both components of the vector-valued IM. When PGA/Sa is the second one, the model of the estimated response value is given by

$$
\hat{R}_{\max }=\beta_{0} \cdot \operatorname{Sa}\left(T_{s}\right)^{\beta_{1}} \cdot\left(\frac{\mathrm{PGA}}{\mathrm{Sa}}\right)^{\beta_{2}}
$$

where $\beta_{0}, \beta_{1}$ and $\beta_{2}$ are the model parameters to be estimated.

This form suggests that maximum pounding force is a function, not only of the energy content in the fundamental period of the free vibrating system, but also of the relative content in the high-frequency range. In addition to this, since the estimate is a function of the product of both terms, there is interaction between them.

Again, the residuals of the regression model $\left(\varepsilon_{i}=\log \hat{R}_{\max }-\log R_{\max , i}\right)$ are assumed to be distributed normally: $\varepsilon \sim N\left(0, \sigma_{\varepsilon}\right)$.

Regression model parameters are estimated using least-squares method. Results will be discussed with reference to a particular case of the parametric study. Although residuals seem to be not far from normal distribution, there is a trend in the upper tail (Figure 6(a)). Also, there seems to be a structure in the plot of residuals against predictions (Figure 6(b)). There is a group of records producing lower than predicted values $(\varepsilon \leqslant 0)$. This happens for all relative intensity values (Figure 6(c)). However, the plot of residuals against $\log (\mathrm{PGA} / \mathrm{Sa}$ ) (Figure 6(d)) indicates that these residuals are concentrated mainly in its lower range.

The records in this group have been identified. They are listed in Table II. Generally, earthquake ground motions can be classified into three types, i.e. motions of pulse style with short epicenter distance, motions of medium duration without clear predominant period and motions of long
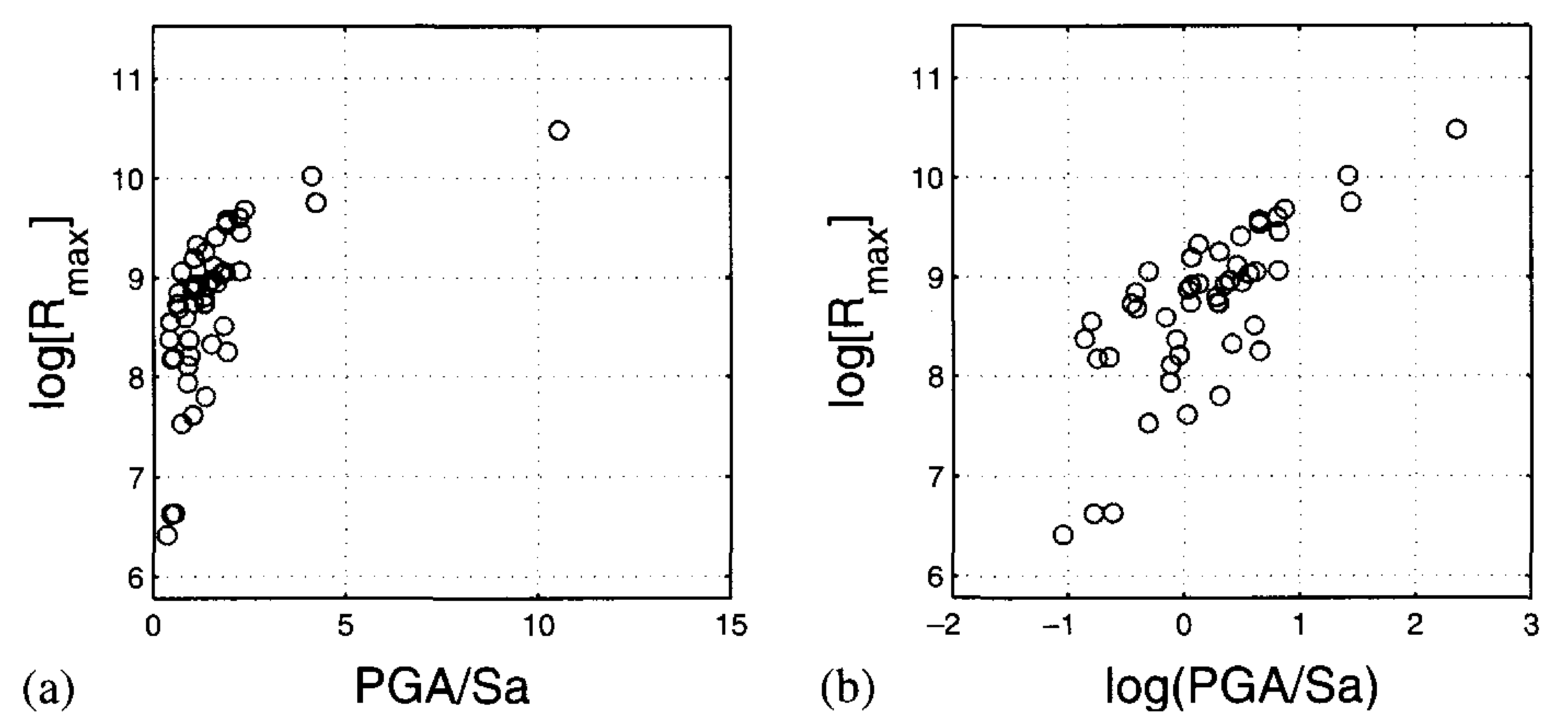

Figure 5. Response values as a function of: (a) PGA/Sa and (b) $\log (\mathrm{PGA} / \mathrm{Sa})$. System parameters: $T_{s}=1 \mathrm{~s}, \zeta_{b}=20 \%, K_{b} / K_{s}=10^{4}$. 

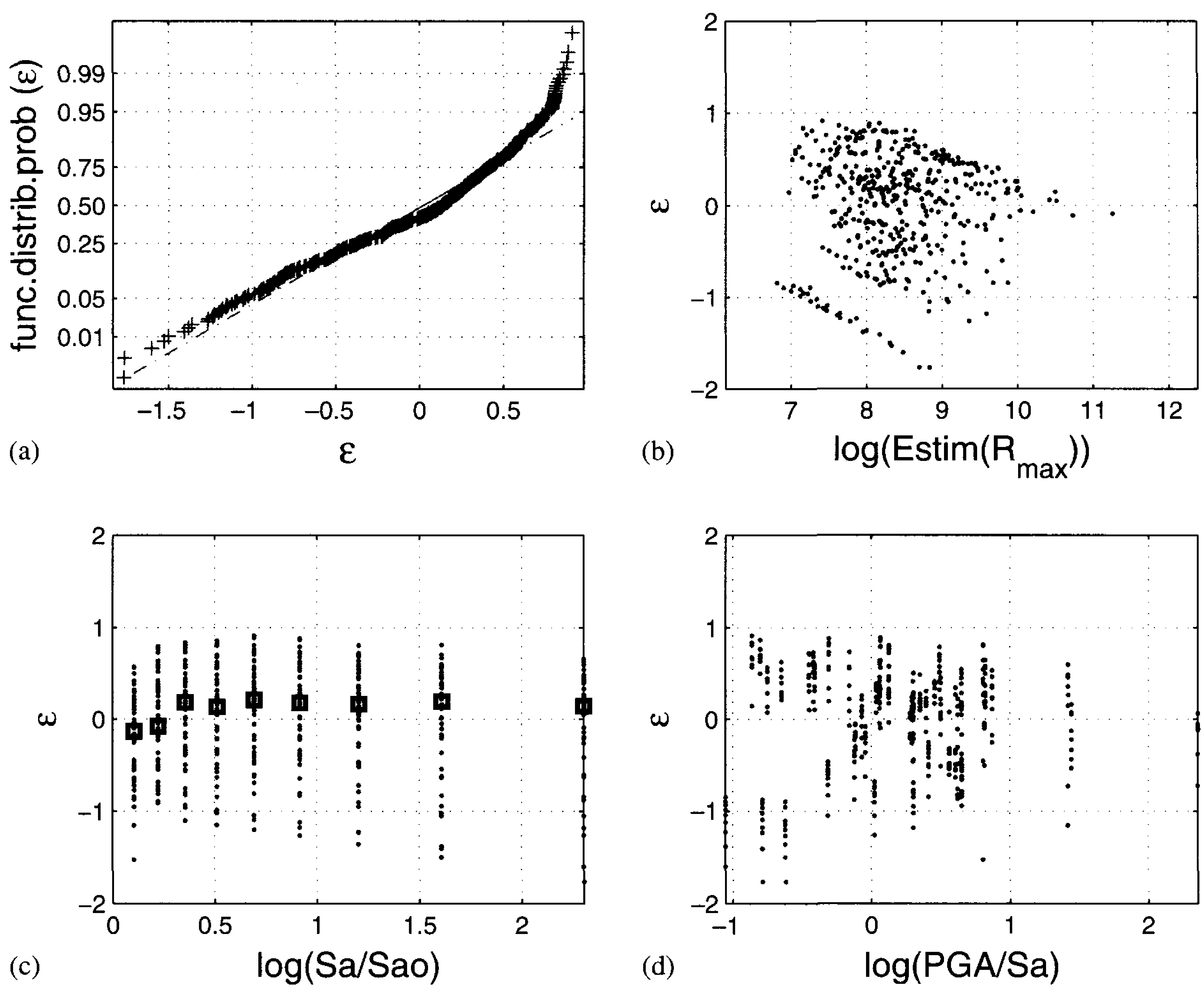

Figure 6. (a) Residuals and estimation plane for $\mathrm{Sa} / \mathrm{Sa}_{0}=2.5$; (b) residuals as function of estimates; (c) normal probability plot of residuals for $\mathrm{Sa} / \mathrm{Sa}_{0}=2.5$; and (d) residuals as a function of $\mathrm{Sa} / \mathrm{Sa} 0$. System parameters: $T_{s}=1 \mathrm{~s}, \zeta_{b}=20 \%, K_{b} / K_{s}=10^{4}$.

Table II. Records excluded for the parametric study.

\begin{tabular}{lclcc}
\hline Event & Date & \multicolumn{1}{c}{ Station } & $M$ & $R(\mathrm{~km})$ \\
\hline Kobe & $17 / 1 / 1995$ & Shin-Osaka & 6.9 & 15.5 \\
Imp. Valley & $15 / 10 / 1979$ & Calexico fire station & 6.5 & 10.6 \\
& & El Centro array \#1 & & 15.5 \\
Loma Prieta & $18 / 10 / 1989$ & Fremont-Emerson court & 6.9 & 43.4 \\
& & Oakland-Title \& Trust & & 77.4 \\
& & Palo Alto-1900 Embarc. & & 36.1 \\
\hline
\end{tabular}

duration with clear predominant period [23]. Analysis of velocity time history, response spectrum and distance characteristics of all records allows concluding that all identified records can be clustered in either the first or the third category. Therefore, in both cases there is a relatively narrow band of frequencies in which a great portion of the energy is concentrated.

Now, the fact that records providing relatively low $R_{\max }$ values were more likely to be found in the lower range of PGA/Sa can be explained. Records belonging to both the above-mentioned 


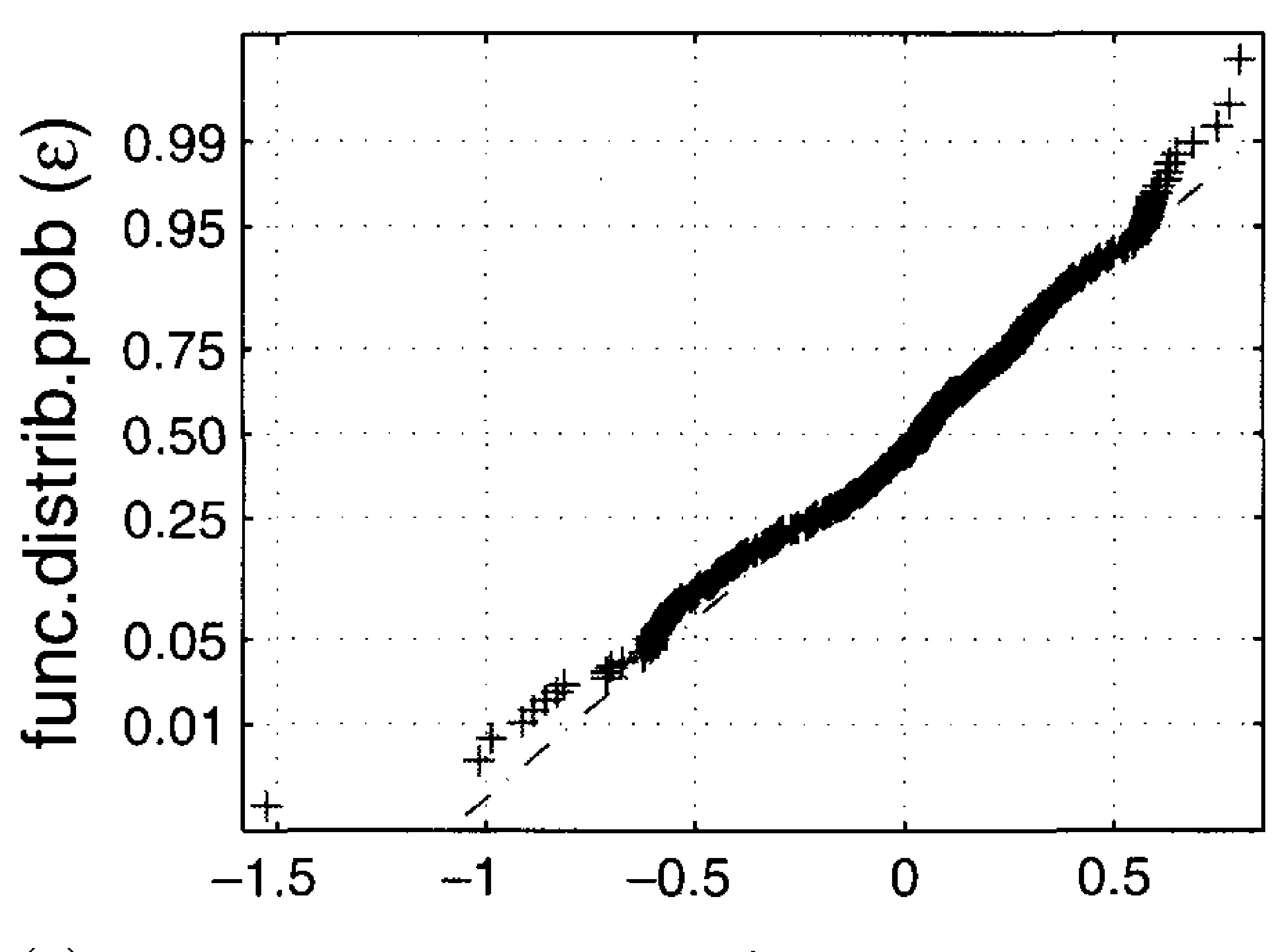

(a)

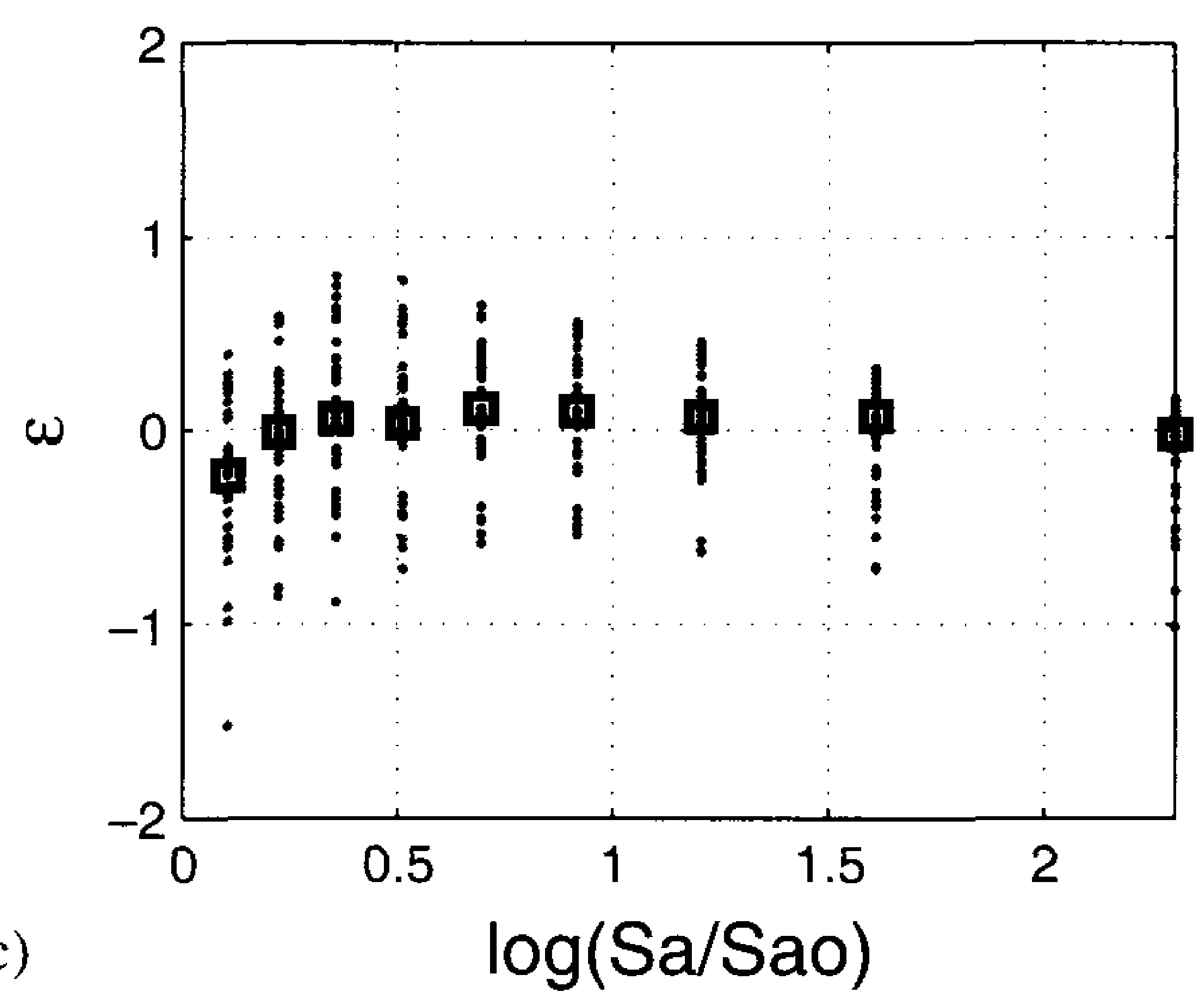

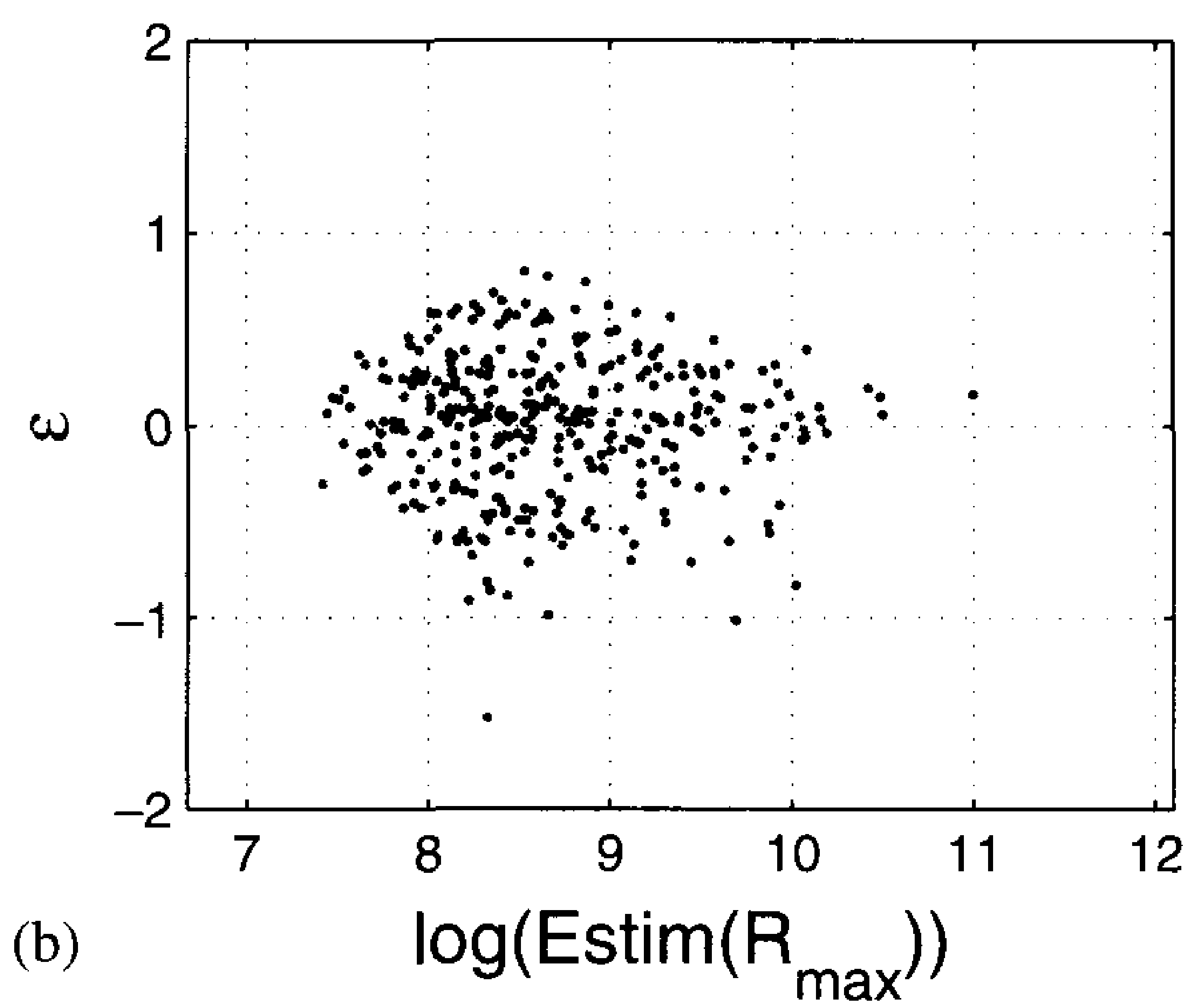

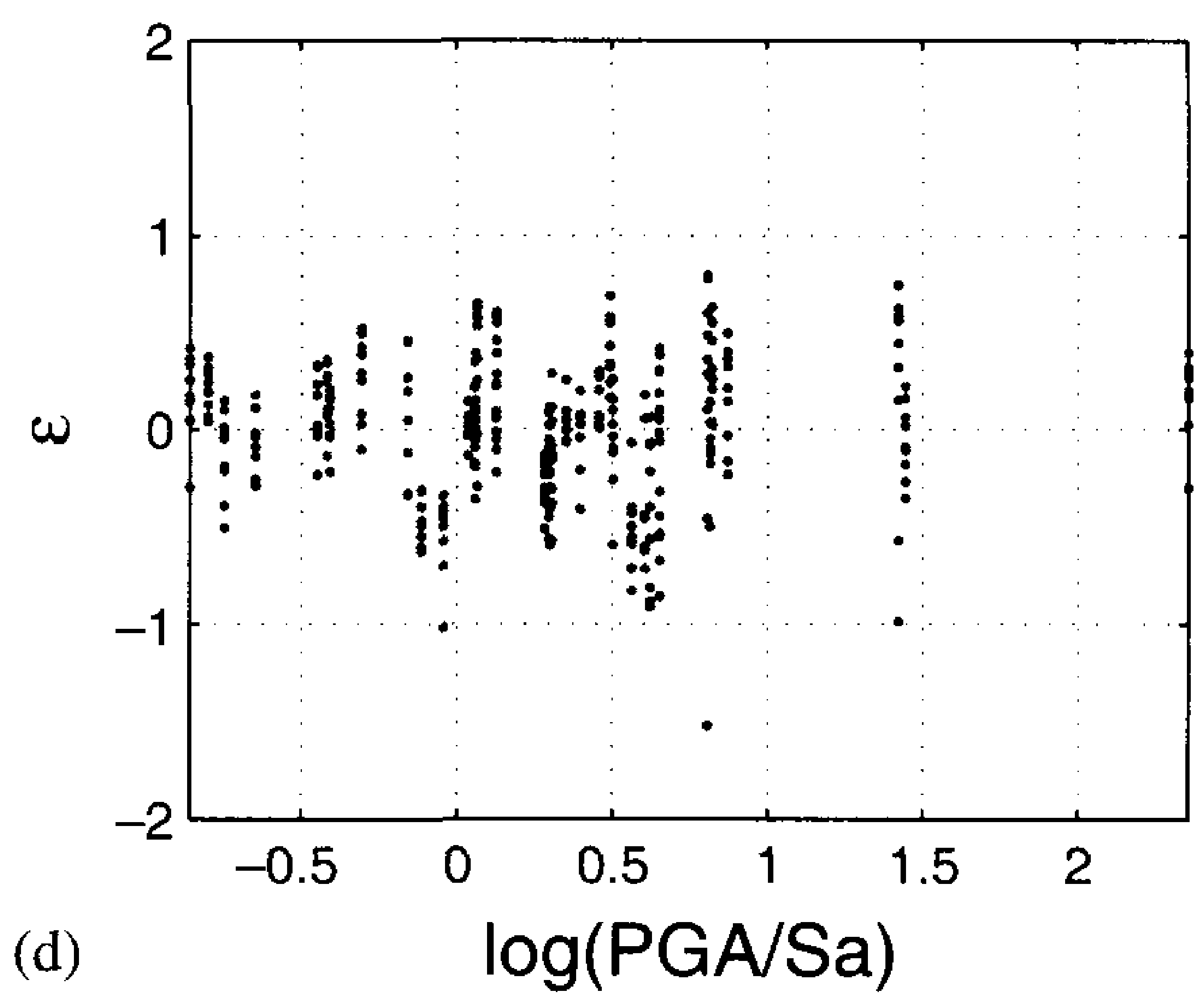

Figure 7. (a) Residuals and estimation plane for $\mathrm{Sa} / \mathrm{Sa}_{0}=2.5$; (b) residuals as function of estimates; (c) normal probability plot of residuals for $\mathrm{Sa} / \mathrm{Sa}_{0}=2.5$; and (d) residuals as a function of $\mathrm{Sa} / \mathrm{Sa} 0$. System parameters: $T_{s}=1 \mathrm{~s}, \zeta_{b}=20 \%, K_{b} / K_{s}=10^{4}$.

categories have relative high values of $\mathrm{Sa}$ for their predominant period. If it happens to be close to the system's one, then the ratio PGA/Sa will be relatively low.

Once those 10 non-typical records have been identified, they are eliminated from the set of samples representing variability in ground motion, and a new regression is performed. Results of the new regression for the same case of the parametric study are presented in Figure 7.

Residuals are closer to the normal distribution, and there is no apparent bias of residuals against predictions. While there is no bias against $\log (\mathrm{PGA} / \mathrm{Sa})$, there is a slight bias against the relative intensity. In order to reduce it, an improvement of the regression model will be tested. It consists of including an additional term in the regression model, trying to capture the non-linear dependence on Sa. This model is presented in Section 7.2.

\subsection{Linear regression model with three parameters}

In order to improve the previous model capturing a second-order dependence, a third parameter is introduced.

$$
\begin{aligned}
\log \left(\hat{R}_{\max }\right) & =E\left[\log \left(R_{\max }\right) \mid \log \left(\operatorname{Sa}\left(T_{s}\right)\right)=x, \log \left(\mathrm{PGA} / \mathrm{Sa}\left(T_{s}\right)\right)=y\right] \\
& =\beta_{0}+\beta_{1} x+\beta_{2} x^{2}+\beta_{3} y
\end{aligned}
$$



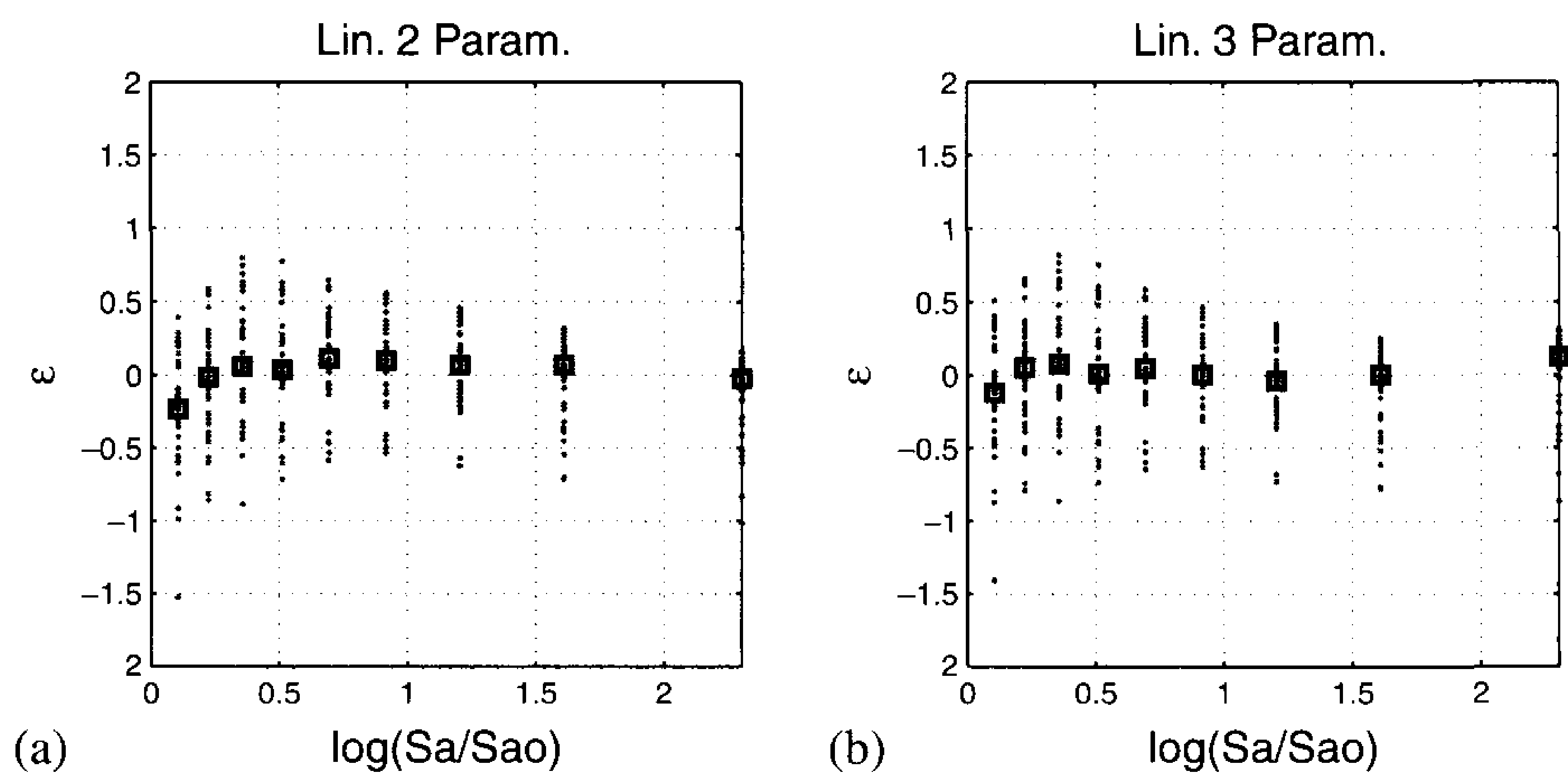

Figure 8. Residuals as a function of $\mathrm{Sa} / \mathrm{Sa}_{0}$. Comparison of two regression models: (a) linear with two and (b) three parameters. Median values conditioned to relative intensity are highlighted.

System parameters: $T_{s}=1 \mathrm{~s}, \zeta_{b}=20 \%, K_{b} / K_{s}=10^{4}$.

This regression model may be interpreted as the one with two parameters, considering the existence of a correction term $g(\cdot)$, which is dependent on both the relative intensity and the new parameter $\beta_{2}$.

$$
\hat{R}_{\max }=\beta_{0} \cdot \mathrm{Sa}\left(T_{s}\right)^{\beta_{1}} \cdot g\left(\mathrm{Sa}\left(T_{s}\right), \beta_{2}\right) \cdot\left(\frac{\mathrm{PGA}}{\mathrm{Sa}}\right)^{\beta_{2}}
$$

The addition of the third parameter slightly reduces bias dependent on Sa. Figure 8 presents the comparison of the plot of residuals against the relative intensity together with the one corresponding to the model with two parameters; otherwise, no other improvement can be signaled for this regression model.

Further improvements using non-parametric regression models have been researched. However, results were not better in the sense that the amount of non-explained variability (measured by $\sigma_{\varepsilon}$ ) was not substantially reduced. The computation effort required for those models, which is much greater than the one needed for linear regression, provides additional arguments against the use of such refinements.

\subsection{EDP estimation}

In order to assess differences in EDP estimation depending on the considered IM, the mean annual rate of exceedance (MAR) for $R_{\max }$ has been computed in two ways, by the means of Equation (2): first, using $\mathrm{Sa}\left(T_{S}\right)$ as IM and Equation (11) as regression model and second, by using a vector-valued IM composed of $\mathrm{Sa}\left(T_{S}\right)$ and the ratio $\mathrm{PGA} / \mathrm{Sa}\left(T_{S}\right)$, and a linear regression model with tree parameters.

In both cases, fictitious probability densities have been considered. Following Baker and Cornell [24], the joint probability distribution for the vector-valued IM was derived from the marginal ones. Although methodologies capable of providing the joint probability distribution already exist (for example, vector PSHA [25]), most of the studies already available provide only hazard information for scalar IMs. Therefore, both IM have been characterized as they would have been in a standard situation. 

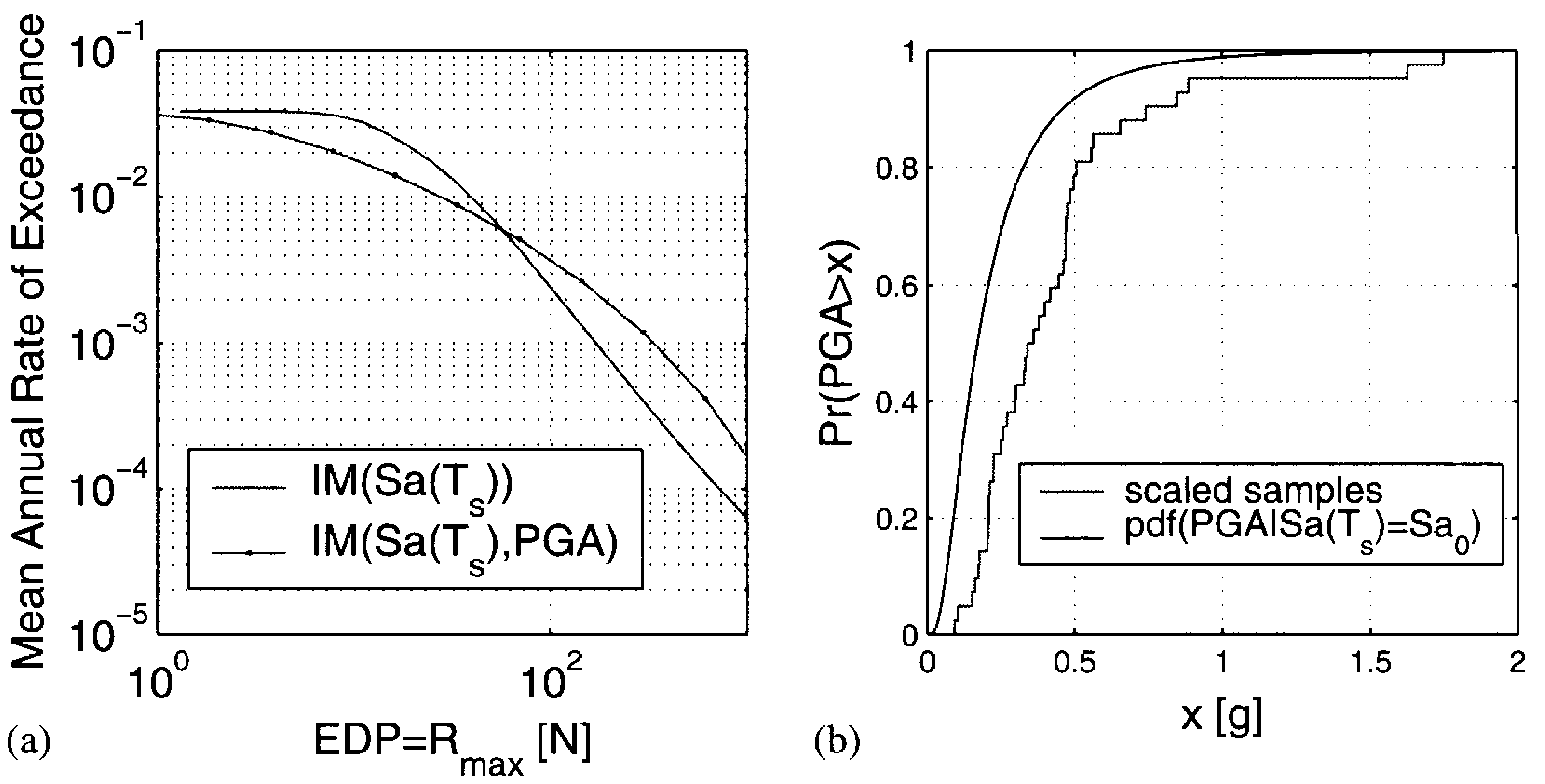

Figure 9. (a) Estimates of MAR of exceedance of $R_{\max }$ using scalar and vector-valued IM and (b) comparison of PGA distribution for samples scaled to $\mathrm{Sa}_{0}$, and the same distribution deduced from Hazard conditional to $\mathrm{Sa}\left(T_{s}\right)=\mathrm{Sa}_{0}$.

Results are presented in Figure 9(a). The horizontal trend for low $R_{\max }$ values is explained by the fact that MAR cannot be greater than the probability of pounding, which is equal to $H\left(\mathrm{Sa}\left(T_{s}\right)=\operatorname{gap} / \omega_{s}^{2}\right)$.

In this case, MAR is overestimated when using a scalar IM for lower values of $R_{\max }$, while it is underestimated for higher values. This can be explained with reference to Figure $9(\mathrm{~b})$. The first line is the distribution of PGA conditional on $\mathrm{Sa}\left(T_{S}\right)$ for the sampled ground motions. The second is the same distribution, derived from the joint probability distribution of both parameters. The conditional distribution derived from the joint probability distribution will be dependent on the selected $\mathrm{Sa}\left(T_{S}\right)$ value. In Figure 9, the intensity level that triggers pounding, $\mathrm{Sa}\left(T_{S}\right)=\mathrm{Sa}_{0}$, has been considered. Therefore, the conditional distribution is representative of intensities producing the lowest $R_{\max }$ values.

Comparing both conditional distributions, it is clear that higher PGA values are more likely when considering sampled records. If all sampled records are considered as equally probable, as implicitly assumed when considering the scalar IM, higher $R_{\max }$ will also be more likely. Therefore, bias in sampled population is translated to $R_{\max }$ estimation, thus producing differences in estimations of the MAR.

When the relative intensity increases, the situation gets inversed, thus explaining the underestimation for the higher range of $R_{\max }$.

\section{ADDITIONAL STUDIES}

\subsection{Choice between $P G A / S a$ and $P G V / S v$ as additional intensity parameter}

Results presented above have been obtained considering an IM made up of Sa and the ratio $\mathrm{PGA} / \mathrm{Sa}$. If the ratio $\mathrm{PGV} / \mathrm{Sv}$ is selected as the additional IM, results are equivalent. The question of which one is better should be answered in terms of non-explained variability, which is measured 

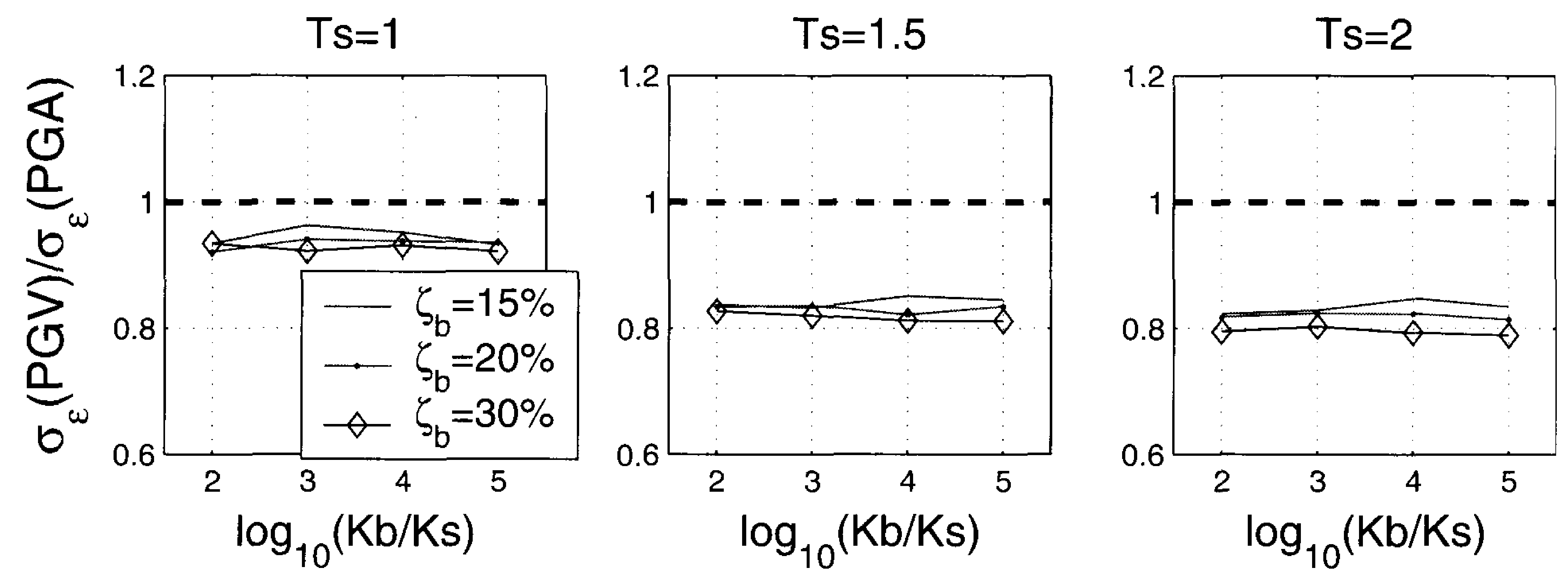

Figure 10. Non-explained variability ratios for different cases of the parametric study.

by the standard deviation of the residuals $\left(\sigma_{\varepsilon}\right)$. A better IM will be more efficient, it will result in lower values of non-explained variability.

In order to investigate this issue, the ratio of standard deviations $\sigma_{\varepsilon, \mathrm{PGV}} / \sigma_{\varepsilon, \mathrm{PGA}}$ has been studied. Values lower than unity will mean that $\mathrm{PGV} / \mathrm{Sv}$ produces lower variability than $\mathrm{PGA} / \mathrm{Sa}$. Figure 10 shows the results. In most of the cases PGV/Sv is more efficient than PGA/Sa, with differences increasing with increasing values of $T_{s}$.

\subsection{Sufficiency of the IM and validity of scaling}

An IM is said to be sufficient if it contains the same information as the magnitude and the distance $(M, R)$. Therefore, no bias of residuals should appear when compared with those values [11]. A linear regression of residuals $\varepsilon$ on both $M$ and $R$ is computed separately. The statistical significance of the slope term, and therefore the sufficiency of the IM, can be quantified by the $p$-value. $p$-value is defined as the probability of finding a regression slope term as large as the one already found when its real value is zero, which is the null hypothesis. A small $p$-value suggests that the estimated slope term is statistically significant, and therefore IM is insufficient.

Figure 11 ((a) and (b)) shows, for one case of the parametric study, the residuals together with the regression lines and $p$-values. It is clear that non-explained variability (the residuals) are much bigger than the variability explained by $M$ or $R$ (the regression). Therefore, $p$-values are not small. The same results have been found for all considered cases, thus proving the sufficiency of the vector-valued IM.

The same line of reasoning has been applied in order to assess the validity of record scaling, which remains an open issue. The underlying question is whether scaling introduces bias in estimated response values. For this study, records have been scaled using factors up to 10 . In order to assess its validity, residuals have been plotted against intensity parameters with their original values. Again, if the original value is important, a bias should appear, and therefore $p$-values should be small.

This time $p$-values will be calculated for each value of the relative intensity; otherwise, the huge variability of intensities might overwhelm any trend. Results show that one cannot conclude that scaling applied to records produces bias (i.e. Figure 12 for the same case of the parametric study). 

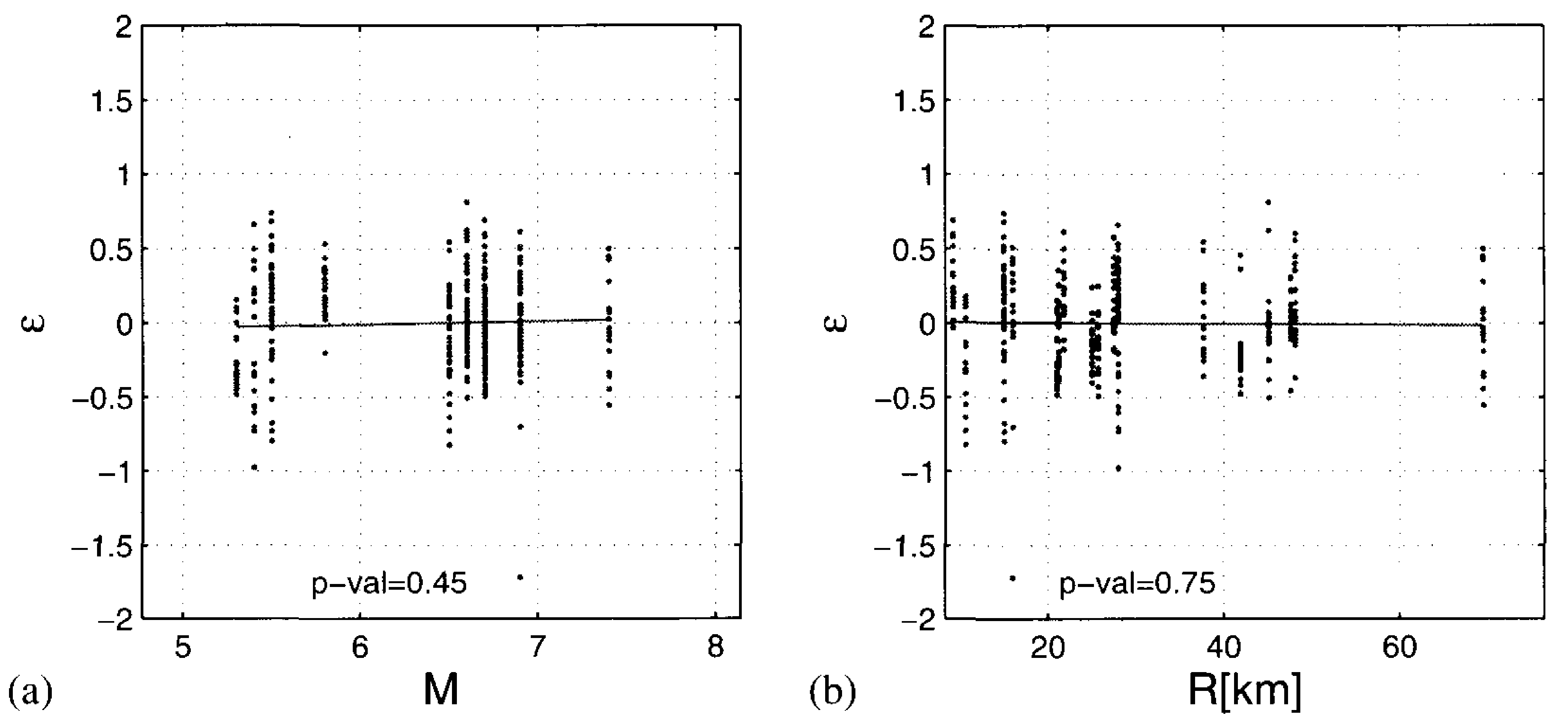

Figure 11. (a) Residuals dependence on magnitude and (b) distance. $T_{s}=1 \mathrm{~s}, \zeta_{b}=20, K_{b} / K_{s}=10^{4}$.
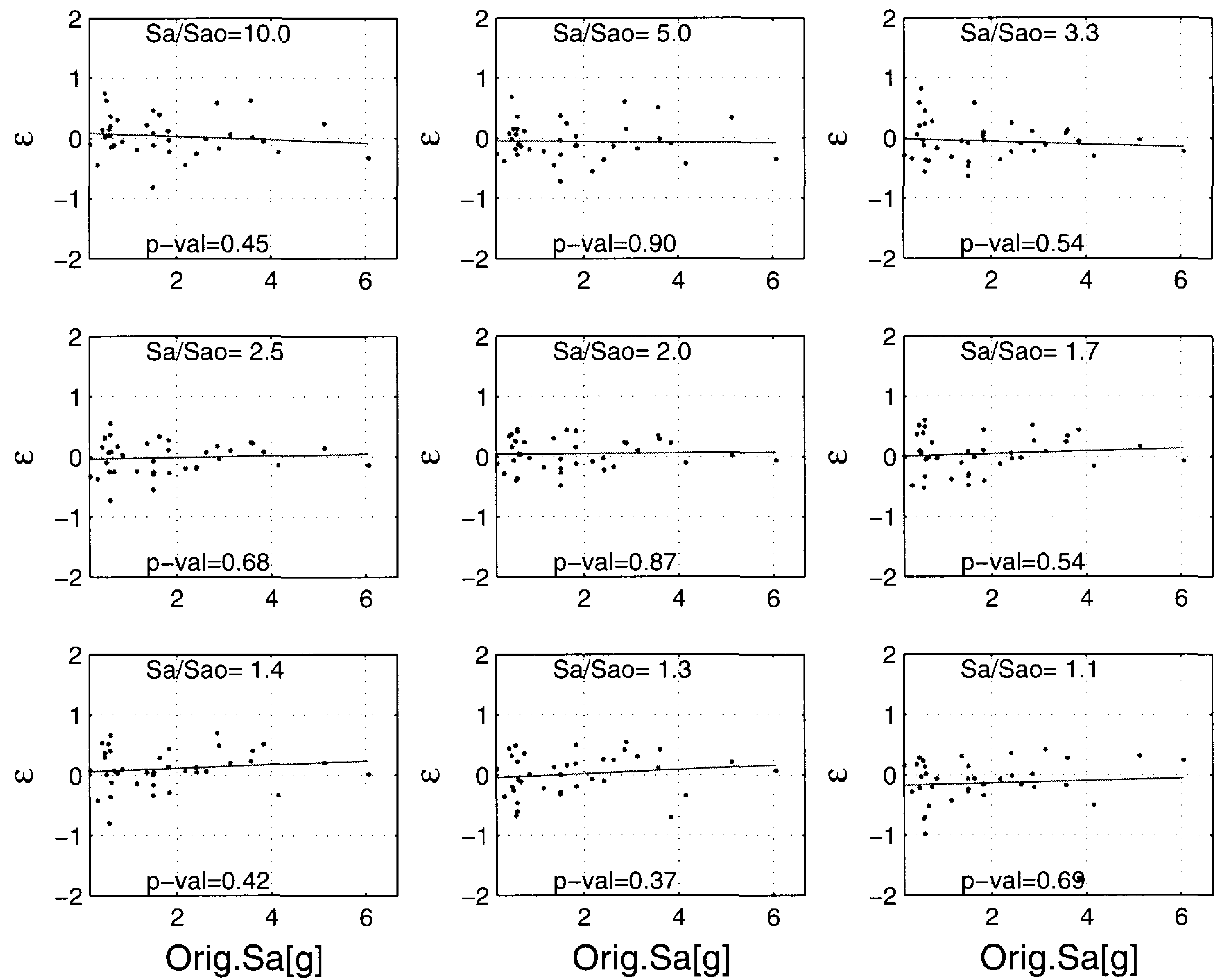

Figure 12. Residuals dependence on the original value of $\mathrm{Sa}\left(T_{s}\right)$ for all considered values of relative intensity. $T_{s}=1 \mathrm{~s}, \zeta_{b}=20, K_{b} / K_{s}=10^{4}$.

\subsection{Extrapolation of estimates for velocity pulses}

The regression model allowing the characterization of EDP conditional on IM has been constructed with a set of records from which records with clearly predominant period have been eliminated. 
Table III. Pulse-type records are selected. Moment magnitude is presented whenever these data are available; otherwise, surface magnitude is used.

\begin{tabular}{lclcc}
\hline Event & \multicolumn{1}{c}{ Date } & \multicolumn{1}{c}{ Station } & $M$ & $R(\mathrm{~km})$ \\
\hline Kobe & $17 / 1 / 1995$ & JMA & 6.9 & 0.6 \\
Northridge & $17 / 1 / 1994$ & Takatori & & 0.3 \\
& & Rinaldi & 6.7 & 7.1 \\
Cape Mendocino & $25 / 04 / 1992$ & Sylmar O.V. & & 6.4 \\
& & C. Mendocino & 7.1 & 8.5 \\
Erzincan & $13 / 03 / 1992$ & Petrolia St. & & 9.5 \\
Imperial Valley & $15 / 10 / 1979$ & Duzce & 6.9 & 2.0 \\
& & El Centro arr. 6 & 6.5 & 1.0 \\
Loma Prieta & $18 / 10 / 1989$ & El Centro arr. 7 & & 0.6 \\
Superstition Hills & $24 / 11 / 1987$ & LGPC & 6.9 & 6.1 \\
Duzce & $12 / 11 / 1999$ & Parach. Test. S & 6.7 & 0.7 \\
\hline
\end{tabular}

In this section the issue of the elimination is studied for the case of pulse-type records. The set of records considered will be enlarged so as to make results more conclusive.

The question is if the estimates calculated from the standard population $\left(\hat{R}_{\max }\right)$ can be used to predict response values for pulse records or not. If not, then both groups should be treated separately in $R_{\max }$ estimation, and therefore the elimination is valid as done before.

In order to analyze this issue, a set of 24 pulses has been selected. They are listed in Table III.

Figure 13 presents, for a particular case of the parametric study, $R_{\max }$ values for pulses and non-pulse records. Regressions computed for both groups separately are also shown. If both groups are homogeneous regarding $R_{\max }$, then their regression models should be statistically equivalent. Therefore, the null hypothesis to be tested for each regression term is Ho: $\beta_{i, \text { non-pulse }}=\beta_{i \text {,pulse }}$, with $i=0,1,2,3$. Again, this is quantified by a $p$-value, measuring the probability of obtaining results as the ones found given the null hypothesis. Low values will mean that the hypothesis of both populations having equal regression models has to be rejected.

All of the cases considered in the parametric study have lead to very low $p$-values concerning parameters $\beta_{0}$ and $\beta_{3}$. Therefore, the null hypothesis must be rejected, and both populations are treated separately for the purposes of EDP estimation. The elimination performed before is thus valid. In the case presented in Figure 13, regression surfaces are clearly different.

It is interesting to note the big scatter of pulse-type record $R_{\max }$ values having similar PGV/Sv ratios, as compared with non-pulse records. This higher non-explained variability may be an inner characteristic of pulse-type records, but it could also be the result of an IM that is less efficient for them. Differences in regression parameter $\beta_{3}$ support this last hypothesis. The lower value of this slope term, which measures the impact on $R_{\max }$ of the relative energy content, is less important for pulse-type records, therefore its ability to predict accurately the response may be lower. Further, research efforts seeking a more efficient IM for pulse-type records should clarify this point. 

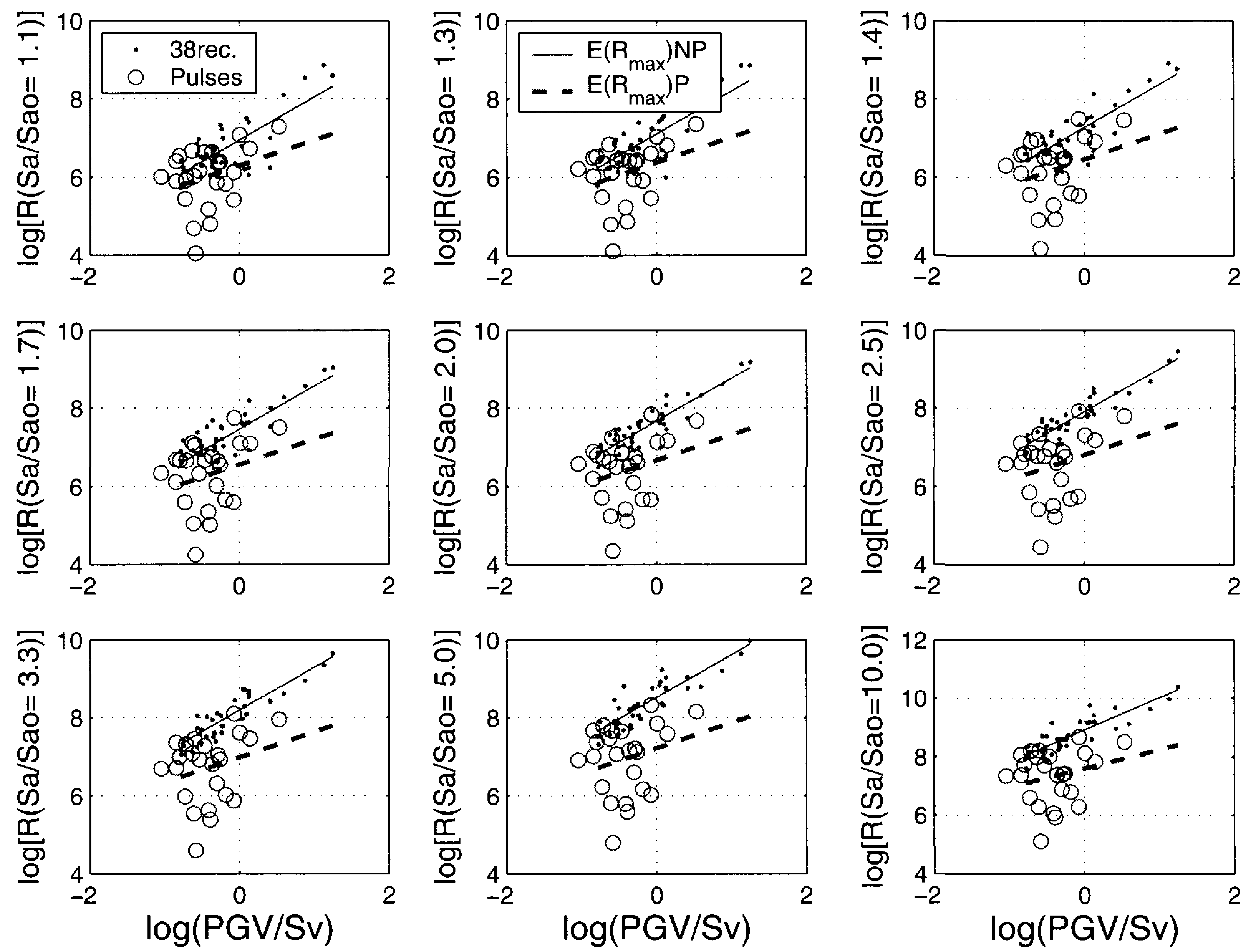

Figure 13. $R_{\max }$ for pulses and non-pulse records, together with their regression surfaces. $T_{s}=2 \mathrm{~s}, \zeta_{b}=20 \%, K_{b} / K_{s}=10^{4}$.

\section{CONCLUSIONS}

Assessment of mean annual rate of pounding forces exceedance has been performed in the framework of the PEER formula. A simplified model that may be used for the longitudinal dynamic behavior of bridges with deck supported by elastomeric or sliding bearings has been presented.

Application of PEER formula requires an a priori selection of IM and EDP. In this case, knowing that EDP is $R_{\max }$, the problem is to choose a suitable IM. This selection has to be made together with the probabilistic relation between EDP and IM.

IM selection has lead to an interesting intermediate result. Similar systems, differing just in gap sizes, enduring similar actions, differing in a scalar factor, with the same relative intensity have been proved to have proportional responses. In addition, the factor is related to gap sizes.

Once the probabilistic relations have been found, some points have been investigated. First, both IMs have been proved to be sufficient. Also, scaling of records produces no bias in estimations. Third, it seems that the second IM is more efficient than the first because it leads to lower nonexplained variability. Finally, it has been found that pulse-type records should be treated separately when estimating EDP conditional to IMs, confirming the assumption made when selecting a set of records representing ground motion variability. 


\section{ACKNOWLEDGEMENTS}

This research was supported by Spanish Ministerio de Fomento, under Project No. 80007/A04. The authors are indebted especially to the engineer coordinating the project, Mrs Pilar Crespo, whose support and advice are gratefully acknowledged.

\section{REFERENCES}

1. Jankowski R. Non-linear viscoelastic modelling of earthquake-induced structural pounding. Earthquake Engineering and Structural Dynamics 2005; 34:595-611.

2. Anagnostopoulos SA. Pounding of buildings in series during earthquakes. Earthquake Engineering and Structural Dynamics 1998; 16:443-456.

3. Lin JH, Weng CC. Probability analysis of seismic pounding of adjacent buildings. Earthquake Engineering and Structural Dynamics 2001; 30:1539-1557.

4. Ma X, Pantelides CP. Nonlinear pounding of bridges in earthquakes. Structures Congress ASCE, Chicago, 17-19 April 1996; 1180-1187.

5. Ruangrassamee A, Kawashima K. Relative displacement response spectra with pounding effect. Earthquake Engineering and Structural Dynamics 2001; 30:1511-1538.

6. Jankowski R. Pounding force response spectrum under earthquake excitation. Engineering Structures 2006; 28:1149-1161.

7. Komodromos P, Polycarpou PC, Papaloizou L, Phocas MC. Response of seismically isolated buildings considering pounding. Earthquake Engineering and Structural Dynamics 2007; 36:1605-1622.

8. Jankowski R, Wilde K, Fujino Y. Pounding of superstructure segments in bridge during earthquakes. Earthquake Engineering and Structural Dynamics 1998; 27:487-502.

9. Cornell CA, Krawinkler H. Progress and challenges in seismic performance assessment, 2000. Available from: http://peer.berkeley.edu/news/2000spring/performance.html (5 January 2009).

10. Kunnath SK, Larson L, Miranda E. Modelling considerations in probabilistic performance-based seismic evaluation: case study of the I-880 viaduct. Earthquake Engineering and Structural Dynamics 2006; 35:57-75.

11. Luco N, Cornell CA. Structure-specific scalar intensity measures for near-source and ordinary earthquake ground motions. Earthquake Spectra 2007; 23(2):357-392.

12. Muthukumar S, DesRoches R. A Hertz contact model with non-linear damping for pounding simulation. Earthquake Engineering and Structural Dynamics 2006; 35:811-828.

13. Azevedo J, Bento R. Design criteria for buildings subjected to pounding. 11th World Conference on Earthquake Engineering, Acapulco, Mexico, 23-28 June 1996. Paper No. 1063.

14. Zhu P, Abe M, Fujino Y. Modelling three-dimensional non-linear seismic performance of elevated bridges with emphasis on pounding girders. Earthquake Engineering and Structural Dynamics 2002; 31:1891-1913.

15. Vamvatsikos D, Cornell CA. Incremental dynamic analysis. Earthquake Engineering and Structural Dynamics 2002; 31:491-514.

16. Pacific Earthquake Engineering Research Centre. PEER strong motion database. Available from: http://peer.berkeley.edu/smcat/index.html.

17. European strong-motion database. Available from: http://www.isesd.cv.ic.ac.uk/ESD/frameset.htm.

18. Cornell CA, Jalayer F, Hamburger RO, Foutch DA. Probabilistic basis for 2000 Federal Emergency Management Agency steel moment frame guidelines. Journal of Structural Engineering (ASCE) 2000; 128(4):526-533.

19. Baker JW. Probabilistic structural response assessment using vector-valued intensity measures. Earthquake Engineering and Structural Dynamics 2007; 36:1861-1883.

20. Pinto PE, Giannini R, Franchin P. Seismic Reliability Analysis of Structures. IUSS Press: Pavia, Italy, 2004.

21. Fajfar P, Vidic T, Fishinger M. A measure of earthquake motion capacity to damage medium-period structures. Soil Dynamics and Earthquake Engineering 1990; 9:236-242.

22. Bozorgnia Y, Bertero V. Improved shaking and damage parameters for post-earthquake applications. SMIP01 Seminar on Utilization of Strong-Motion Data, 2001; 1-22. 
23. Newmark NM, Rosenbluth E. Fundamentals of Earthquake Engineering. Prentice-Hall: Englewood Cliffs, NJ, 1971.

24. Baker JW, Cornell CA. Correlation of response spectral values for multicomponent ground motions. Bulletin of the Seismological Society of America 2006; 96(1):215-227.

25. Bazzurro P, Cornell CA. Vector-valued probabilistic seismic hazard. Seventh U.S. National Conference on Earthquake Engineering, Boston, MA, 21-25 July 2002; 10. 